\title{
OS HOMENS DOS DÓRIS: BERNARDO SANTARENO E O FAZER DO MAR UM TEXTO PARA PRODUZIR SENTIDO
}

\section{DORIS' MEN: BERNARDO SANTARENO AND THE ACT OF MAKING THE SEA A TEXT TO PRODUCE, TO MAKE SENSE}

http://dx.doi.org/10.11606/issn.2175-3180.v12i23p41-62

\author{
Rosemary Conceição dos Santos ${ }^{\mathrm{I}}$ \\ José Aparecido da Silva ${ }^{I I}$
}

\section{RESUMO}

Este trabalho trata das crônicas de Bernardo Santareno presentes na obra Nos mares do fim do mundo (1959) e de seu dialogismo com a peça teatral O lugre (1959), do mesmo autor. Na primeira, o autor, tratando de troças, foca a personalidade (As peias do balanço); de contação de causos, a tradição e a memória (Antigamente). Psiquiatra de formação, a Santareno não passou despercebidos a humilhação ( $\mathrm{O}$ bobo), o desespero ( $\mathrm{O}$ ciclone), a descoberta (Funeral marítimo), a esperança (Frederikshaabs), a superstição (Os fantasmas da Groenlândia; O lobisomem) e a angústia (As mulheres dos mais rijos navegadores do mundo) evidenciadas na condição social e pessoal dos personagens, pescadores de bacalhau em sua maioria, e dos que por eles são lembrados, esposas, filhas e amigos. Em cada crônica, a identificação santarena da dignidade que os eleva de um aparente anti-heroismo à condição de heróis. Heróis da resiliência, da superação e do aprender a estarem sozinhos consigo mesmos. Uns, aprendizes, despreparados para lidar com o amor e a morte. Outros, maduros, enfrentando a solidão, o perecimento e o finamento dezenas de vezes em seus dóris. Ao final, o que aprenderam sendo contado a um médico-escritor que viajava com eles. Núcleos narrativos que são, estas crônicas preparam caminho para que Bernardo Santareno redija a peça teatral O lugre (1959), leitura santarena da pesca do bacalhau nada condizente com o rumo traçado pela propaganda Salazarista de então. Tratados, em sua ambivalência, na sequência deste ensaio, em ambas, o exercício do confinamento e do distanciamento social, com todas as exigências e consequências que ambos impõem à condição humana.

\section{PALAVRAS-CHAVE}

Bernardo Santareno; Mar; Produção de sentido.

I Universidade de São Paulo, São Paulo, Brasil.

II Universidade de São Paulo, Ribeirão Preto, Brasil.

\section{ABSTRACT}

This work deals with the chronicles of Bernardo Santareno present in the work In the seas at the end of the world (1959) and his dialogism with the play O lugre (1959), by the same author. In the first, the author, dealing with mockery, focuses on personality (As peias do balance); storytelling, tradition and memory (Formerly). A trained psychiatrist, Santareno did not go unnoticed through humiliation (The fool), despair (The cyclone), discovery (Funeral maritime), hope (Frederikshaabs), superstition (The ghosts of Greenland; The werewolf) and anguish (The women of the toughest navigators in the world) evidenced in the social and personal condition of the characters, cod fishers in their majority, and those who are remembered by them, wives, daughters and friends. In each chronicle, the Santarem identification of dignity that elevates them from an apparent anti-heroism to the status of heroes. Heroes of resilience, overcoming and learning to be alone with themselves. Some, apprentices, unprepared to deal with love and death. Others, mature, facing, dozens of thimes, loneliness, perishing and fineness dozens of times in their cod-fishing ships. In the end, what they learned by being told to a doctor-writer who traveled with them. Once they are narrative nuclei that they are, these chronicles prepare the way for Bernardo Santareno to write the play O lugre (1959), a santarena reading of cod fishing not consistent with the course set by the Salazarist propaganda of that time. Treated, in their ambivalence, following this essay, in both, the exercise of confinement and social distance, with all the demands and consequences that both impose on the human condition.

\section{KEYWORDS}

Bernardo Santareno; Sea; Production of sense. 


\section{INTRODUÇ̣̃̃O}

Nome literário de Antônio Martinho do Rosario (1924-1980), Bernardo Santareno, autor de poesia, prosa e dramaturgia, foi considerado o dramaturgo de mais alta inspiração nos quadros da modernidade portuguesa (Moisés, 2012, p. 658). Em sua obra dramática, os diálogos imaginados e a composição cênica, frutos que são da fraseologia, poesia e superstição populares, "assinalam uma evolução no sentido da denúncia das repressões inquisitoriais ou fascistas, com integração dos recursos e obsessões já anteriormente pessoais numa estruturação sugerida pelo teatro épico de Brecht" (Saraiva, 1996, p. 1119).

De acordo com Mendonça (1971), em Santareno, as primeiras peças são voltadas mais ao estilo do drama aristotélico, enquanto as últimas são mais aproximadas do estilo brechtiano. O Lugre (1959), exemplo das primeiras peças, resgata o diálogo entre o ator e o público, originalmente presente no teatro grego aristotélico, no qual o coro, grupo de artistas que comentam com voz coletiva a ação dramática que estava ocorrendo, é um intermediário entre ator e plateia.

A diferença? No coro das tragédias gregas, o objetivo de tal recurso era intensificar a ação (Souza, 1997), enquanto que, no coro do teatro épico de Brecht, era de provocar o chamado efeito de distanciamento (Willett, 1967). Provocando uma quebra na ação, Brecht despertava no espectador uma estranheza que visava alcançar um efeito didático, de forma que o público percebesse que as condições sociais são transitórias e passíveis de mudança. O lugre (1959), de vertente existencial e fórmula dramática, é peça teatral voltada à linha do período naturalista-realista, com o trágico destacando-se como característica fortemente presente neste estágio, aliada ao caráter poético e explorando temas existenciais, sociais e políticos, características, estas, que se intensificarão nas obras finais do autor.

Nos mares do fim do mundo (1959) ${ }^{1}$ e O lugre (1959)2, crônicas e peça teatral respectivamente, datam, ambas, de 1959, e, voltadas que são à achacação, tratam de diversos aspectos da vida de pescadores bacalhoeiros portugueses em mares da Terra Nova e Groenlândia, em especial das

\footnotetext{
${ }^{1}$ Entre parênteses, a data de publicação da obra. Neste ensaio, as citações estão sendo extraídas da edição de 1997. 2 Entre parênteses, a data de publicação da obra. Neste ensaio, as citações estão sendo extraídas da edição de 2019.
} 
tensões da vida a bordo e da relação cotidiana com o perigo, perante as quais os mesmos, ficcionalizados, exibem as mais diferentes reações.

A importância de sua contextualização? Época em que em Portugal vivia-se o Estado Novo, regime político autoritário, autocrata (com poder absoluto e inquestionável) e corporativista (com o Estado controlando as instituições social, política e econômica), que vigorou no país durante 41 anos ininterruptos, desde a aprovação da Constituição de 1933 até sua queda pela Revolução de 25 de Abril de 1974, esclarece, para o leitor, o fato de Salazar, de acordo com Cruz (2017, p. 7), com clara intencionalidade política de impedir a invasão da Península Ibérica pelas forças alemãs, ousar manter a frota do bacalhau no mar durante a II Guerra Mundial, ocasionando a morte de dezenas de homens de dóris (pescadores) bombardeados por submarinos nazistas.

Neste contexto, em Marques (1998, p. 348), iniciada a II Guerra Mundial em 1939, Portugal, de modo diplomático, impôs-se a tese de neutralidade perante o conflito e esforçou-se para evitar o ingresso da Espanha, por afinidade ideológica, juntamente com a Itália e a Alemanha. Nesta "neutralidade", entretanto, o país abasteceu de matérias-primas ambos os blocos conflitantes, angariando um lucro não alcançado pelos portugueses desde os finais do século XVIII. Entretanto, em Marques (1998), apesar de a eclosão do conflito ter dado a Salazar alguns anos de trégua interna, o que impediu a invasão "foi o ataque intempestivo de Mussolini à Grécia e a sua incapacidade de levar os Gregos de vencida. Obrigado a intervir para evitar a abertura de uma frente aliada nos Balcãs, Hitler adiou ou pôs de parte o projecto, deixando a Península em paz" (Marques, 1998, p. 394).

Por adição, em Marques (1998, p. 409), registra-se que, em 1958, iniciando-se a segunda grande crise política do regime português devido à crescente insensibilidade de Salazar, seguida de sua incompreensão acerca do mundo em que vivia, não tardou para que os oposicionistas, os neutros e os próprios adeptos da situação reclamassem maior abertura política, bem como, modificações e reformas administrativas, além de opções governamentais em relação ao país, a Ultramar e ao estrangeiro. Eram novas vozes, portanto, que, despertadas seja pelos fatos reais seja pelas denúncias efetuadas pelos meios culturais, como a literatura de Santareno, por exemplo, desconstruíam as redes propagandistas do regime. 
Nas palavras de Cruz (2017, p. 10), denúncias, estas, que faziam a oligarquia do regime ter pesadelos com tudo que pudesse questionar a "paz celestial" conquistada nos "mares terrenos", e que angariaram a Santareno, na época, desprezo e ataques às caracterizações desencantadas e impiedosas da violência, da disciplina rigorosa, das inquietações, das revoltas e do sofrimento dos homens dos dóris "que se faziam ao mar em condições miseráveis".

\section{SIMPLICIDADE E COMPLEXIDADE EM SANTARENO}

Em Nos mares do fim do mundo (1959) e n'O lugre (1959), de Bernardo Santareno, considerar a articulação interpretativa, em detrimento da articulação estrutural, permite-nos identificar a importância pontual de contextos históricos em diferentes momentos do enredo, e não só quando referências lineares e casuais vão sendo narradas. Uma vez que a narrativa simples vincula-se ao mítico e ao ideológico, a complexidade de outras, em Santareno, se deve ao rompimento que promovem com o mítico e a ideologia real para promoção da abertura semântica, direção na qual a crítica vem se encaminhando há tempos.

Privilegiando a oralidade, a narrativa simples de Nos mares do fim do mundo (1959) busca fortalecer comportamentos sociais e literários que, despretensiosos, trazem à pena o modo ingênuo, natural e primitivo de se contar histórias. Por sua vez, objetivando analisar os mitos em que repousam os valores sociais de qualquer tempo, a encenação complexa de O lugre (1959), de imediato se posiciona para criticar o comportamento cognitivo dos homens no decorrer da história, lançando intencionalmente, em alguns momentos, o anti-herói que, de maneira insólita, reorganiza o enredo. Logo, o mito e a ideologia unidos em uma, denunciam falsidades em outra. Entretanto, ao denunciar estas últimas, a encenação complexa não estaria, também, recriando um novo mito, uma nova ideologia?

Obviamente que sim. Simples ou complexa, narrativa e encenação são construções a preencherem o vazio das não ideias dos protagonistas e atores, a partir de uma ideia primeira, ainda que não original, do próprio autor, então crítico e observador. Cabe aqui a ressalva que muitos fazem sobre o não ineditismo dos enredos, a saber, que tudo que podia ser escrito já o foi, e que o novo não passa de seguidas repetições de um determinado original. Entretanto, a ressalva de outra característica que distingue narrativa simples de encenação complexa repousa no fato de, enquanto a 
primeira busca a primazia das personagens simples, com foco destacado em um mínimo de protagonistas, a complexa introduz estranhamentos que subvertem o simbólico, direcionando-o ao alegórico nas entrelinhas.

Tais constatações, em Nos mares do fim do mundo e n'O lugre, nos levam a associar o significado final fechado à simplicidade narrativa, ao passo que, o ambíguo, o inconsciente, o imaginário em aberto, admitindo toda a amplitude de significados, à complexidade encenativa. A utilidade destas informações? Esclarecer que, em análise literária, são os enredos que determinam a teoria, ou técnica, que deve ser empregada para sua melhor compreensão, e não vice versa. De modo similar, são esses horizontes, e o que lhes faltam, que ditam qual conteúdo buscar na obra para exemplificar o que importa ao leitor apresentar.

Em Nos mares do fim do mundo e n'O lugre, portanto, ler o simples ou o complexo depende de quais caminhos a imaginação santarena apreciou caminhar ou desconstruir, para melhor ousar e conhecer. Certamente, a caracterização por Santareno efetuada é denunciativa, ditada tanto pelo que já sabemos das imposições ditatoriais ao ser humano, quanto pelo que o autor, observando a condição humana nos dóris e no lugre, se permitiu descobrir, e ainda querer continuar conhecendo, haja vista Santareno ter embarcado como médico mais de uma vez na frota bacalhoeira, a saber, de 1957 a 1959, composta pelas embarcações David Melgueiro, Senhora do Mar e Gil Eannes, que se dirigia todos os anos para a Terra Nova e Groenlândia. Mas como Santareno conseguiu adentrar ao interior daqueles homens?

\section{SABER OUVIR}

Delia Steinberg Guzmán, Diretora Internacional da Nova Acrópole, organização portuguesa iniciada em 1957, voltada a ações de cultura, filosofia e voluntariado, publicou uma mensagem sobre a arte de ouvir que, seja na ditadura salazarista, seja nos tempos difíceis que temos vivido, merece destaque. Afirma ela que ouvir é poder fazer a comparação com o que nós pensamos e ter a oportunidade de calibrar, após essa comparação, o peso dos nossos pensamentos. Em Santareno, ouvir é saber intervir no momento oportuno, sem interromper bruscamente e sem passar por alto o que o outro está a dizer. Seja Nos mares do fim do mundo (1959), seja n'O lugre (1959), a relação entre o médico que ouvia e os homens que narravam deixa entrever desde linguagens e palavras imprescindíveis a expressões vulgares e ferinas que exaltam toda a violência e a agressividade contida 
em homens que se sentem mal compreendidos, sós e maltratados, injustamente, pela vida.

Em As peias do balanço (SANTARENO, 1997, p. 9), a personalidade, conjunto de características psicológicas que determinam os padrões de pensar, sentir e agir, ou seja, a individualidade pessoal e social de alguém, quando demonstrada no comportamento de Zé Claro, ao saber-se motivo de chacota dos demais, permite conhecer o comportamento adaptativo do personagem, "E sentou-se em cima do saco, agora triste, quase a chorar: Andam a fazer pouco de mim...". Zé Claro, revelando a Santareno aspectos superficiais e aparentes de sua vida cotidiana, como, por exemplo, deixar-se explorar como contrapeso de cabos náuticos para equilibrar os movimentos do David Melgueiro, reaviva, no médico, suas reflexões sobre o quanto o ambiente social contribui para modelar o desenvolvimento do indivíduo na sociedade. Imposta ao rude homem, a despeito do mal estar que isso the causava, rege, enquanto não percebida por este, sua própria permanência ali.

De modo geral, a formação da personalidade, processo gradual, complexo e único a cada indivíduo, é referencial do qual se podem partir focalizações para análises literárias entre organismos e ambientes (Leite, 2002), viabilizando-nos afirmar que, no caso de Zé Claro, a permanência de sentimentos ou acontecimentos infantis em sua vida mental e comportamental de adulto, assim como a evolução de conflitos emocionais e afetivos à intensificação neurótica, como no caso das peias, são formas diferentes de uma neurose que se mostra alternativa única para expressão de anormalidades e conflitos de expressão.

Falar de seus sentimentos ao médico foi uma forma de transmitirlhe o que de vivo lhe atormentava o íntimo. Falando, Zé Claro percebia que ele mesmo, a despeito de sua humildade, era, também, um homem que tinha algo para dizer; algo sério, algo importante. Ouvi-lo, por sua vez, fazia Santareno compreender que havia naquele simples homem do mar uma alma cheia e uma atenção desperta para deitar mão em qualquer momento daquilo que fazia parte de seu mundo interior. Ao conversar, Zé Claro aprendia o que era sentir-se ouvido, bem como a importância de se ter as ideias claras para não se enredar em repetições inúteis.

O que Santareno conseguia com isso? Mostrar ao leitor que, seja na ficção, seja na sociedade como cidadão, a conversação era o que permitia intercâmbio preciso entre os que sabem defender suas opiniões sem, por isso, 
deixarem de ouvir as razões dos seus interlocutores. Em tempos de ditadura, principalmente, para conversar havia, sobretudo, que se saber ouvir.

Por sua vez, esse saber ouvir também apresenta seu papel na contação de casos, na manutenção de tradições e na preservação do memorialístico (Lima, 2013). Em Antigamente (SANTARENO, 1997, p. 13), a menção do autor sobre a forma de narrar dos homens dos dóris, "isto foi mesmo assim, senhor doutor - dos tempos bárbaros da pesca do bacalhau!...", é excerto de origem complexa, introdutor, na narrativa, do aspecto mnemônico voltado à construção de virtudes (Yates, 2007, p. 133). Os homens dos dóris, pescadores do mar de Portugal que, em pequenos e frágeis botes, os "dóris", se aventuraram na arte da pesca do bacalhau, à linha, pelos mares navegados por seus antepassados, ao serem evocados nessa crônica, recuperam a imagem dos seres solitários e destemidos do passado luso que descobriam sua fragilidade humana ante um mar vigoroso e senhor da natureza, assim como, segundo Lourenço (2012, p. 134), do Sebastianismo, em sua persistência e sucessivas metamorfoses de mito ajustado a um (i)mortal reino português.

Na mesma crônica (SANTARENO, 1997, p. 15), a tentativa de preservação da superstição nas considerações fatalistas de tio Zé sobre o capitão de Ílhavo, morto há pouco tempo, que, por vingança, assassinou colegas quando atracados em terra:

- Era um home mau, um danado, senhor doutor! Entre as mulheres, tinha fama de lobisome... E eu já na digo nada! Lembrar-me a mim... olhe que isto é tão verdade, senhor doutor; como eu chamar-me Zé: Vi, vi eu, com estes dois olhos que a terra, ou o mar, há-de comer! Durante três dias e três noites, antes de ele morrer, os corvos, um bando de dez pelo menos!, não lhe desampararam a casa: nem os gritos, nem as pedras, nem os foguetes foram capazes de os tresmalhar. Sempre ali, cerrados, a voarem como doidos em redor do prédio!... Aquele tinha manhas com o Demónio, senhor doutor!...

Ouvindo-lhes as contações, Santareno podia comparar o que ouvia com o que a sociedade de então pensava, tendo a oportunidade de calibrar, após essa comparação, o peso de seus registros. Neste caso, saber ouvi-los foi sua melhor maneira de saber narrar. Em Seltzer (2008, p. 3-4):

Três mil homens, para trinta e três navios. Homens que desde a sua juventude não passaram um único Verão em casa, que quase nunca estiveram com as suas mulheres durante o nascimento dos seus filhos. 
[...] Cada homem terá de enfrentar o oceano sozinho. O barco a que cada um confia a sua vida, o dóri, é feito de tábuas de madeira, e tem apenas dezasseis pés de comprimento. Para cada homem, um dóri, escolhido por sorteio. Um processo cheio de superstição: alguns números são considerados de má sorte; outros, de boa sorte. [...] Os homens têm esperança de que lhes calhe um número que lhes trouxe uma boa pescaria no passado, e rezam para que não lhes saia o número de um que se afundou no mar com um amigo.

Esses homens dos dóris, pescadores que eram dos mares frios do Atlântico Norte, ao terem suas vidas metamorfoseadas às de heróis no santareno imaginário literário do mar, também permitiram ao autor pontuar casos de humilhação, nos quais a experiência vivenciada mostrou diminuir a autoestima da pessoa que sofreu a humilhação. É o caso da crônica O bobo (SANTARENO, 1997, p. 17), sobre fato ocorrido no lugre Granja que, historicamente, voltado a trazer para Portugal o bacalhau que os outros lugres pescavam nos bancos, fazia o transporte de mercadorias entre Lisboa e Génova quando veio a naufragar chegando a Terra Nova (ilha a noroeste do Oceano Atlântico, no Canadá), ao chocar-se com uma rocha por conta do nevoeiro que se fazia, então.

$\mathrm{Na}$ crônica, narra-se a vergonha sentida por Albino algarvio, bobo do veleiro. Habituado a ser assediado moralmente pelos tripulantes, que ora "puxavam-lhe a camisola", ora achincalhavam-no com alcunhas e risos destemperados, chega ao seu limite quando o cozinheiro Ricoca sugere, ironicamente, aos demais que a falta de cartas ao bobo talvez se devesse por sua mulher ter se interessado por outro. Troça, esta, que, semeada em uma personalidade torturada intimamente, que vinha sonhando com formas de vingança, ou com a própria morte, acaba por assassinar o cozinheiro e o ajudante.

Tais desordens psicológicas, biológicas e socioculturais humanas, assim como ocorre com ansiedade, somatização e dissociação, entre outras, encontráveis em todas as culturas, e nos mais diversos tempos, ainda que não assim nomeadas, permitindo ao leitor observar serem os personagens de O bobo capazes de uma repressão cada vez maior dos instintos, conhecida de antropólogos e sociólogos nos estudos de processos civilizatórios de ajustamentos, que, atingindo seu ápice, alcança os aspectos noturnos e doentios da personalidade humana.

$\mathrm{O}$ inconsciente, ligado dinâmica e continuamente à consciência numa relação causa-efeito, ao ser retomado por Santareno, nessa crônica, 
reafirmando que, com exceção das personalidades patológicas, encerradas em seus próprios mundos, e dos despersonalizados, que refletem as condições em que se encontram, eliminar a importância do contexto na personalidade ocasiona focalização redutora desta, que desconsidera, por exemplo, indivíduos capazes de ajustar-se, ou reagir de modo realista, sem serem alterados pela realidade do ambiente ao qual se inserem.

$\mathrm{Na}$ esteira dos fatos narrados pelo autor a partir de episódios de tragédias envolvendo dóris e lugres, em O ciclone (SANTARENO, 1997, p. 24), abordando o desespero da tripulação, e, em Funeral marítimo (SANTARENO, 1997, p. 40), a descoberta subjetiva a que estas tragédias leva, Santareno demonstra para o leitor que o comportamento resulta de uma interação organismo-ambiente cuja descrição realística tanto se aplica a um personagem quanto a uma pessoa.

No primeiro caso, através das emoções retratadas dos tripulantes em meio ao mar em fúria, tementes pela própria sobrevivência:

Aquilo levantou-se de repente e durou uma noite inteira. O Infante de Sagres atirado ora acima, ora abaixo, pelos dedos descomunais do mar, lambido ferozmente pelos cabelos zumbidores do vento, era uma coisita, a fugir entre os urros da deusa Fúria! Foi em 1949, na Terra Nova, no mês dos ciclones - Setembro. E ninguém ainda pôde esquecer... Entre os lugres, pela telefonia, o terror escorria nas vozes aflitas dos capitães: ciclone assim, tempestade tão bruta, não havia memória!... - Jesus, Jesus! Ah, Senhora dos Aflitos! (SANTARENO, 1997, p. 25-6)

No segundo, através da descoberta de ser aviltante, para aqueles homens do mar, qualquer explicação científica que lhes contestasse a própria superstição:

Foi no Santa Mafalda. O homem apareceu morto de manhã, no beliche: Doença súbita. O navio estava no alto mar, a mais de vinte e quatro horas de navegação para terra: Era pois indicado preparar-lhe um funeral marítimo... Então, lá no fundo, da proa, o Chico de Alcântara avançou, por momentos olhou sobranceiro, quase trocista, os companheiros, e depois, em passos seguros dirigiu-se para o cadáver, prendeu-lhe o gancho e, decidido, fê-lo descer para o mar. Quando, passados dias, o Chico começou a inchar - os pés primeiro, depois as pernas e por fim o corpo todo - não houve ninguém na companhia que não pensasse o mesmo: Foi castigo!...Todos baixaram a cabeça, como quem reza. Só eu, no meio dos pescadores, tentei um sorriso incrédulo...logo cortado pela profunda e dolorosa gravidade com que 
os outros me isolaram. E o silêncio envolveu-nos a todos. (SANTARENO, 1997, p. 31-35)

Entretanto, psicólogo e psiquiatra que era, Santareno, no parágrafo final de Funeral Marítimo (SANTARENO, 1997, p. 35), excluído por todos por seu descrédito, opta por uma observação que o identifica como profissional e narrador-personagem capaz de lidar, na vida e na obra, com analogias, metáforas e ambiguidades. Ao afirmar sobre o mar, "Nunca, como neste momento, eu senti que tal não é verdade: Antes variada, rica, cheia de incidências, de músicas longínquas, de carícias rolantes, de ocultas ameaças...", o autor esclarece compreender as ideias e sentimentos que se atropelavam na mente daqueles homens do mar, habituados às coisas mais simples da vida. Mas, ao passo que eles tomavam a imensidão marítima azul como um labirinto para dormirem o sono eterno, ele o tomava como esclarecedor, dia após dia, daqueles arquétipos que se comportavam à luz do que lhes ditavam os mitos.

$\mathrm{Na}$ psicologia de Santareno, a interpretação psicológica de biografias, incluindo a sua, auxiliava-o no (re)conhecimento de personalidades de homem e ambiente de acordo com o contexto em que se encontrava. Contexto, este, no qual o estudo do comportamento descrito busca, alicerçado na lógica psicológica, delinear o caráter e o registro de atitudes que o sujeito humano explicita, ou deixa subentendidas, ao realizá-las. De modo similar, também os leitores respondem, a seu modo, ao que leem, o que faz, das respostas à literatura, "efeitos" que determinados enredos comunicam aos leitores.

Em Frederikshaabs, título referência à vista do maior glacial do mundo, na Groenlândia, a imagem retratada na descrição:

Pescamos a $63^{\circ}$ de latitude norte... Gelos eternos. No mar sereno, na neve que cai em silêncio, no ar límpido e calmo, oculta-se não sei que segredo branco e cruel, não sei que perdido gesto dum deus impassível e gelado... E passam lentamente, os grandes icebergues: Poderosos, na realidade terríveis, a matéria de que são feitos, grácil e imaculada, fálos parecerem só decorativos, mesmo amáveis... Mentem! Erguidos com a substância do riso, no fundo escondem os olhos da violência. Um desses blocos de gelo parece uma grande mão decepada e lívida: nem sequer lhe faltam as veias, em complicadas nervuras dum azul belíssimo... Outro é como uma máscara fúnebre, adolescente e nobre, em cujos olhos brancos o sol fez ninho. E passa ainda um cisne hierático e real vogando sereno sobre a orla do tempo...Diluídos em 
finíssima neblina, esquecidos no eco (antigo de mil anos!), os anjos do Silêncio impregnam tudo com a penumbra da sua natureza. (SANTARENO, 1997, p. 37-38)

denota, primeiramente, o sentimento de esperança evocado pelo branco em cor, logo descortinado pela figurativização com que a mente, reconhecendo e associando formas de seu mundo de imagens aos quadros que vê, os alegoriza. Esperança de quê? Esperança simbólica pela ventura do processo de pesca ancestral em que vivem homens de dóris e homens de lugres, convivendo, ambos, diariamente, com a morte. Branco de início e branco de fim. Metáforas compensatórias do empenho diário a que se dedicam, em conjunto, pela própria sobrevivência.

Imaginário concebido pelo senso comum, ou seja, adquirido por meio da observação, vivência e experiências realizadas em seu trabalho em alto mar, ou relembradas pelos pescadores e passadas de geração para geração, o imaginário santareno, aqui, difere do imaginário pessoal, no qual é a subjetividade da pessoa que se apresenta ao inconsciente, e do imaginário coletivo, em que as imagens de um povo e de uma cultura é que são apresentadas ao leitor. No caso, o acervo de subjetividades e imagens culturais que o autor associa aos homens de dóris e aos homens de lugres se revela como uma resposta à angústia humana diante do branco início e finitude da vida.

Em se tratando de um autor de conhecimentos psicológicos e psiquiátricos, uma reflexão sobre o processo mental através do qual concebemos uma imagem, relembrando, aqui, que, tal qual para Aristóteles, em Frederikshaabs, a mente humana, como retratada por Santareno, também não é capaz de pensar sem imagens, com ela representando o que não existe no nosso mundo imediato.

Por sua vez, em Os fantasmas da Groenlândia (SANTARENO, 1997, p. 41), a retomada de uma passagem cara aos portugueses, a saber, a do Velho do Restelo, em Os Lusíadas, de Camões. Neste, ao narrar a partida de Vasco da Gama para os mares a serem descobertos, Camões traz à cena um ancião, na saída do porto português, a saber, o Velho do Restelo, simbolizando os pessimistas que não acreditavam no sucesso da epopeia dos Descobrimentos Portugueses. Este, então, põe-se a admoestar os ocupantes das naus, e as viagens, argumentando que os navegadores, imbuídos de cobiça por fama, glória e riquezas, encontrariam infortúnios para si e para o povo português. 
Em Santareno (1997, p. 41), o excerto que retoma tal passagem

- Eh, gentes! Oiçam o conselho de quem lhes quer bem: Na vão! É morte certa rapazes... O velho que assim arengava, o ti'Rufino, estava no meio. À volta, os outros todos, alguns ainda meio despidos. No mar, mal começava a luzir a madrugada. Lá onde os homens conspiravam, à proa, apenas a luz débil de duas lâmpadas. E o velho, caído o lábio inferior, trémulo de indignação, mostrava os dois incisivos, grandes e amarelos, ornamentos únicos da mandíbula ossuda...

assinala, também, a superstição dos pescadores sobre almas penadas (SANTARENO, 1997, p. 43), "- Se fosse só isso...se fosse só isso, ti'Refino! Penam por lá almas do outro mundo, fiquem a saber... Parece qu'em certos dias, de tão desesp' radas qu' andam, as alminhas 'té levantam os navios ao ar: os barcos ficam grandes, altos como torres!", sobre o lume que não conseguiriam atear, sobre o forte gelo que aprisionava os barcos sem nunca mais deixá-los retornar para casa, sobre o medo de morrerem de frio e de sede, enfim, sobre o receio de enfrentar aqueles mares tão longínquos e tão estranhos. Medos, entretanto, que se submeteram à violência do capitão Cajeira, maleficamente apelidado de capitão Caveira, homem de urros medonhos, gestos brutais, olhos sangrentos de tão avermelhados a saírem das órbitas, que havia prometido ao armador que iria com aquele navio e aquela tripulação à Groenlândia, e de lá só retornaria a Portugal quando o porão estivesse abarrotado de bacalhau.

O final da viagem? Tal qual n' Os Lusíadas, retornaram todos ufanos de glória. Já o capitão Cajeira, envelhecido com o passar dos anos, reaparece rabugento, tossindo e impertinente, a contar suas façanhas sentado em um banco de jardim da vila onde morava. Cabe aqui uma ressalva: ainda que estes pescadores adquiram, ao longo de suas viagens e enfrentamento de obstáculos, a condição de heróis, esta se apresenta como resultado de sua resiliência para sobreviver em condições inóspitas e retornar para os seus ao encerramento das mesmas. Entretanto, diferentemente de Os Lusíadas, em que os personagens são apresentados ao leitor já imbuídos da eterna tradição da grandeza, do heroísmo e do patriotismo, os personagens de Santareno são apresentados, inicialmente, em sua condição humana, em seus medos e em suas fragilidades à luz de um Neorrealismo Português afeito ao comprometimento com a transformação humana do mundo e a permanente articulação entre o individual e o coletivo. Superados tais sentimentos negativos durante as 
viagens, os personagens de Santareno adquirem autoconfiança, alcançando a mudança preconizada no período, e revelando-se heróis.

Por sua vez, na crônica O lobisomem (SANTARENO, 1997, p. 49), tematizada similarmente em torno da superstição, tem-se o relato de Santareno sobre todos os navios retornarem a Portugal com o convés repleto de peixe enquanto um único navio, em meio a eles, retornar sem nada, parecendo estar sendo alvo de praga ou bruxaria. Como isso afetava a tripulação?

O ambiente estava a tornar-se explosivo: em arco tenso os nervos, a lógica riscada pelos vidros, os olhos mais antigos do instinto de novo à superfície... Sim, a coisa não era natural: ali pesava uma qualquer influência estranha e demoníaca, uma estrela fria e terrível, um olhar sobre-humano e malsão, talvez um pecado oculto e nefando atraindo o castigo... (SANTARENO, 1997, p. 49-50)

Eis que, em um diálogo entre os tripulantes, surge a suspeita de aquela dificuldade em pescar o bacalhau dever-se a um caso semelhante, ocorrido com um tal ti'Manel Torto, conhecido como lobisomem. Desde então, corrida a suspeita no navio, todos passam a espionar uns aos outros, "reservados", "atentos" e "ferozes". Numa noite, um dos ajudantes de máquina, ainda bem jovem, acordou sobressaltado com uivos de lobo, gemidos e praguejamentos emitidos pelo terceiro-maquinista que, dormindo, tinha novamente um de seus torturantes e espalhafatosos pesadelos. Aterrorizado, não tardou a associar ao terceiro-maquinista o lobisomem que suspeitavam existir no navio e a este trazendo mau agouro em relação à sua pesca em alto mar. Relatado o caso aos companheiros, estes indicaram ser o rapaz a pessoa mais adequada a dar um fim naquilo. Ele conhecia o camarote do "lobisomem" melhor que os demais e saberia o que deveria ser feito.

O rapaz, após muito relutar, viu-se obrigado pelos demais à ação e, temeroso, preparou uma forquilha de arame com a qual, atacando o terceiro-maquinista no braço, do camarote fugiu desesperado. Contado o feito aos demais tripulantes, o rapaz, chorando, foi refugiar-se em seu beliche. Acordando, o terceiro-maquinista viu uns arranhões estranhos no braço e, vendo a forquilha no chão, logo compreendeu o ocorrido e, interpretando-o como uma brincadeira do segundo-maquinista ou do piloto, logo voltou a dormir. Entretanto, no dia seguinte, eis que a sorte da pesca mudou seu curso, o que fez todos, incluindo Santareno narrador, entenderem não se tratar, o ocorrido, de uma coincidência. 
A superstição, crença sem fundamento racional e lógico que, normalmente, se baseia em situações recorrentes ou coincidências eventuais, em Santareno (1997), tanto em Os fantasmas da Groenlândia quanto em O lobisomem, é apresentada ao leitor como elemento que faz com que os homens dos dóris criem certas regras ilógicas sobre o desconhecido, as quais os fazem terem medo de coisas inofensivas e acreditarem em coisas sem fundamento à medida que a elas atribuem a capacidade de conceder sorte ou azar a ações, coisas e pessoas. Em Vyse (2014), trata-se de tradicional necessidade humana de controlar todos os aspectos da vida, incluindo até mesmo os que não dependem do indivíduo.

Por adição, de modo similar à aproximação do episódio do Velho do Restelo, de Camões, a passagem também pode ser identificada como crítica ao espírito da raça portuguesa, tida, tradicionalmente, como a de um povo aventureiro, cavalheiresco e destemido: a despeito de os personagens de O lobisomem (SANTARENO, 1997) terem ido desbravar as águas geladas da Groenlândia, não o foram como pescadores valentes em busca de descobertas e conquistas, mas, sim, obrigados por um capitão que não aceitara sua covardia, seus receios e determinismos causais, os quais os faziam enxergarem tudo como fenômenos relacionados a vida e a morte, enfim, a um mundo sem previsibilidade que influenciava de forma negativa suas expectativas e ansiedades.

Por sua vez, em As mulheres dos mais rijos navegadores do mundo (SANTARENO, 1997, p. 58), é a figura conservadora da mulher solteira, que demora a casar, filha de pais já idosos e sem recursos suficientes para lhe arranjar um bom casamento, que é inicialmente apresentada ao leitor. Em Santareno (1997, p. 58):

\footnotetext{
Sente-se velho, a mulher cada vez mais acabada e a rapariga ainda em casa, solteira: Terá que casá-la bem, para que fique amparada, senhora do seu próprio lar. Mas para tal - é o costume da Fuzeta - o ti'Fausto precisa de juntar dinheiro que chegue para lhe comprar o enxoval e uma casita também: Será capaz, terá ele ainda forças para isso?
}

Entretanto, tal caracterização vem a propósito de Santareno destoála da figura feminina que quer apresentar em particular: a da mulher que, casada com os homens dos dóris, pescadores que se arriscavam nos mais longínquos mares da terra, trabalhavam na Fuzeta, antiga freguesia portuguesa do concelho de Olhão, seja em fábricas de peixe ou preparando o biqueirão, espécie de peixe abundante nas regiões mediterrâneas e na 
costa atlântica da África e da Europa, enquanto aguardavam seus maridos voltarem ao lar. Ou das mulheres que, nos dez meses do ano em que se separavam de seus maridos, cavavam, semeavam, ceifavam e colhiam.

Neste contexto, pontuando casos particulares ocorridos com os tripulantes do navio, Santareno apresenta ao leitor outras mulheres envolvidas na mesma sorte: a pequena, ainda inocente, a aguardar ansiosa a chegada do pai; as já moças, enfeitadas de ouro, despertando interesse dos pescadores jovens quando, com a mãe, ali vinham receber o pai; as que se amasiaram com outros na ausência do marido; as que se casaram no mesmo dia em que os maridos partiram para a pesca do bacalhau, deixando-as sozinhas em terra; e, por fim, a que, tendo a mãe adoecido, ainda soube desta cuidar, bem como, dos irmãos e da casa, sem se esquecer de escrever ao pai que, em alto mar, vai acompanhando sua luta por todos e sua espera por ele.

Em Portugal, pontualmente durante o Estado Novo, período em que Nos mares do fim do mundo foi publicado, o esforço para se conservar a mulher no seu posto tradicional, a saber, como mãe, dona-de-casa e em quase tudo submissa ao marido, era um fato. Santareno, por sua vez, ao apresentar qualitativa e valorosamente seu papel social e privado enquanto companheira dos homens dos dóris, apresenta sua crítica à uma sociedade que a relegava a um plano secundário na família e na sociedade em geral. $\mathrm{Na}$ esteira disso, o autor também alertava para a imposição do trabalho doméstico, bem como, para a proibição de reconstituição familiar feminina uma vez que o divórcio era proibido. Nestes casos, eram as crianças consideradas ilegítimas; e a mulher, uma "adúltera", "que, enqu'anto o marido labuta no mar, meses e meses, pra ganhar o sustento dela e o dos filhos, se vai deitar com outro calquer" (SANTARENO, 1997, p. 63).

Época em que a mulher praticamente não tinha direitos, o Estado Novo é apresentado por Santareno como um período em que o trabalho feminino se deparava frequentemente com grandes limitações: à mulher era vedado o acesso a determinadas profissões, como, por exemplo, a magistratura, a diplomacia e a política, além de não lhe ser concedido o direito de acesso a determinados lugares considerados próprios somente para a ocupação masculina.

Em Magalhães (1998), a situação da mulher antes da Revolução dos Cravos, de 25 de Abril de 1974, que depôs o regime ditatorial do Estado Novo, vigente desde 1933, e que iniciou um processo que viria a terminar com a 
implantação de um regime democrático e com a entrada em vigor da nova Constituição a 25 de abril de 1976, marcada por forte orientação socialista, era a de muitas mulheres não poderem se casar com quem queriam, bem como, mesmo casadas, não poderem alterar a própria propriedade, se enfermeiras não poderem se casar, se professoras não poderem casar com homem que tivesse um vencimento inferior ao dela, e, de modo geral, precisarem pedir autorização para casar, trabalhar e ir para o estrangeiro. Quando, então, autorizadas, essa autorização saía em Diário da República, indicando o nome do senhor fulano de tal autorizado a desposá-la.

Em cada crônica, portanto, a identificação santarena da dignidade que eleva os personagens de um aparente anti-heroismo à condição de heróis. Heróis da resiliência, da superação e do aprender a estarem sozinhos consigo mesmos. Uns, aprendizes, despreparados para lidar com o amor e a morte. Outros, maduros, enfrentando a solidão, o perecimento e o finamento dezenas de vezes em seus dóris. Ao final, o que aprenderam sendo contado a um médico-escritor, psicólogo e psicanalista, que viajava com eles.

Núcleos narrativos que são, estas crônicas preparam caminho para que Bernardo Santareno redija a peça teatral O lugre (1959), leitura santarena da pesca do bacalhau nada condizente com o rumo traçado pela propaganda Salazarista de então.

\section{OS PORQUÊS DE UMA PEÇA DE TEATRO}

Já em sua Introdução, O lugre (SANTARENO, 2019, p. 7) traz a contextualização do tema como "uma aventura humana cujas imagens culturais oscilam entre o registo épico e o drama". Praticada regularmente desde os séculos XV e XVI no Atlântico Noroeste, "em especial nos baixios da Terra Nova e junto ao Labrador, a pesca longínqua do bacalhau adquiriu um estatuto lendário em diversos países europeus e mesmo na América do Norte":

Da grande aventura humana restam lendas vivas (os próprios pescadores, os capitães e os demais tripulantes) e... um riquíssimo património material composto por objectos náuticos, instrumentos de pesca e todo um conjunto de artefactos que evocam as longas viagens e as duras jornadas de trabalho. Sobre a saga bacalhoeira dos navios de pesca à linha ficaram também algumas obras literárias e diversos testemunhos cinematográficos. (SANTARENO, 2019, p. 7) 
Por sua vez, em Garrido (2008, p. 5), a pesca do bacalhau é apresentada por uma ótica mais política e econômica que simbólica: tratava-se, sem dúvida, "de compor e impor uma versão reelaborada do "nacionalismo português', "um exercício hermenêutico assente num inventário de ideias e imagens (ou representações) cunhadas pelo Estado em torno da sua própria intervenção no domínio das pescas", buscando restabelecer a soberania do Estado-nação imperial. Em outras palavras, o regresso de Portugal ao mar era ação que combinava "folclorismo de validação etnográfica e a estética de massas do fascismo", visando certificar a reconquista da soberania econômica do Estado.

Em Cruz (2017, p. 9), sendo Portugal o primeiro produtor mundial de bacalhau salgado seco, esclarece-se que tal cenário era conseguido com violenta repressão dos trabalhadores. A pesca, setor carente, de grandes contingentes de mão de obra, acabou sendo controlada pelo governo, num recrutamento que impunha um regime de matrícula obrigatória para os armadores. Neste contexto, ainda segundo Cruz, o pescador era obrigado a se manter no barco da campanha anterior, eliminando-se a possibilidade do oferecimento de seu trabalho a um novo capitão que lhe conseguisse melhores condições. Essa imposição, proposta em 1927, é consagrada em lei em 1937, ano em que uma revolta coletiva de pescadores descontentes com a situação, resulta numa greve que abala o salazarismo. O resultado? Segundo Cruz (2017, p. 9), uma repressão implacável dos pescadores, com inúmeras prisões e a publicação de um decreto de recrutamento obrigatório. "Passam a ser considerados desertores os pescadores que se recusem a embarcar no mesmo navio da campanha anterior".

Se, em Os mares do fim do mundo (1959), Santareno figurativiza a classe dos pescadores, pareando sua imagem histórica de comunidade nacional das gentes do mar com suas observações psicológicas e psiquiátricas sobre os comportamentos por ele observados em cada um dos pescadores que ali conhecera, em O lugre (1959), com os atores Albino, corcunda de 50 anos a quem chamam de Marreco; Miguel, jovem frágil e belo de 17 anos; Zé Sol e Tó Verde, respectivamente, moreno e louro fortes e belos, ambos de 25 anos; Ti' João Das Almas, contramestre do lugre e homem de respeito em seus 60 anos; Zé Espada e Tó Maria, ambos primeira linha (os melhores entre os maduros) de, respectivamente, 35 e 34 anos; o Capitão, alto, dominador, 50 anos; o Imediato, de 30 anos; Toino Nazareno, de 20 anos; o grupo de pescadores maduros (10 a 12, homens 
experientes e adultos), verdes (5, jovens que, pela primeira vez, seguem na pesca do bacalhau) e moços (5, rapazes que não pescam, mas se dedicam a vários trabalhos de bordo ), atuando nos Mares da Terra Nova e Grande Banco, Santareno, dramatiza, no palco, a imagem dos navegantes e heróis do mar, para narrar a dureza de suas vidas de pescadores portugueses a serviço da frota bacalhoeira, permeada tanto pelas tensões da vida a bordo quanto pela relação quotidiana com o perigo, perante os quais cada um deles reagia de forma diferente.

Até então, nada diferente do mote das crônicas de Nos mares do fim mundo: um retrato do confronto entre o homem e a natureza marítima selvagem, realçando as diferentes facetas do ser humano. Entretanto, reforçada a particularidade destes homens ali estarem forçados não pelo seu medo, como nas crônicas, mas pelo governo de seu país, interessado, este, numa campanha de propaganda do regime salazarista, a peça O lugre busca desconstruir a ideologia de fundo historicista, interessada, especificamente, na corporativização do "trabalho pesqueiro nacional".

A luta para sobreviver a tempestades contínuas, visando o ganhapão e a subsistência de si e da família, como ilustrado no seguinte excerto (SANTARENO, 2019, p. 24):

TODOS - Rema! Rema! Rema! Rema!...

CAPITÃO (Cuja voz domina o tumulto) - Zé Sol! Ó Zé Sol! Experimenta com o bicheiro?!... (Precipitadamente, Zé Sol vai buscar uma longa vara terminada por gancho forte e, desesperado, tenta prender com ela o bote perdido.)

(...)

CAPITÃO - Uma bóia... atirem-lhe uma bóia! (Corridas.) Eh, com mil raios, então essa bóia?! (Um Pescador arremessa a bóia para o mar) Agarra, Toino! Agarra! Agarra!... (SANTARENO, 2019, p. 24):

se, por um lado, se apresenta psicologicamente verdadeira, principalmente nos casos em que o autor buscou na psicologia as figuras e relações interpessoais que utilizou na concretização do drama, por outro, quando exposta ao interesse político-ditatorial do salazarismo, revela-se situação complexa, que reclamam reflexões e observações mais agudas que a simples possibilidade de serem encaixadas numa mística nacionalização tradicionalista da "cultura popular" portuguesa.

Aqui, não é a verdade psicológica buscando realçar a noção de realidade da criação santarena, que dará valor artístico às crônicas de Nos 
mares do fim do mundo, mas, sim, como essa mesma realidade foi manipulada pelo poder salazarista para realçar a coerência e a complexidade da união figura mítica e manutenção de poder para, assim, se obter um viés político carismático e empreendedor que se estabelecia sobre o setor pesqueiro como uma fortíssima dimensão oligárquica de poder.

Santos (2002), a partir da análise de particularidades do salazarismo e da instrumentalização propagandística que este regime fez da arte de interpretar, possibilita a interpretação de que o teatro, em Portugal, sobretudo a partir dos anos 50, apresenta uma submissão que é pouco a pouco transformada em resistência. Por sua vez, em Reis (2005, p. 206-7), discorrendo sobre os caminhos do teatro da ocasião, Santareno afirma entender que o teatro se apresenta, por excelência, como denúncia seguida de esperança político-social e de contemplação desesperada do absurdo.

O regime salazarista, optante da esquiva ao invés do confronto, da discrição em detrimento ao alarido e da prevenção no lugar da repressão, ao agir sorrateiramente, tem suas entrelinhas descobertas pelas encenações teatrais. Santareno, denunciando a retomada ufanista do povo escolhido para vencer o mar, fachada mítica que encobria a realidade de vigilância opressiva governamental, alcança o mérito devido aos que conseguiram historicamente desafiar as interdições do autoritarismo. Seu O lugre, portanto, atuando como sinal vaticinante da nescessária democratização de um país que o salazarismo tentou emudecer e imobilizar.

Em Nos mares do fim do mundo, ficção narrativa, é a mediação do autor narrador que, situando personagens no ambiente, bem como, descrevendo sua aparência física, sua realidade psíquica e onde e como vivem, entre outros, gera o contexto físico e psíquico que chega ao leitor. Logo, trata-se de uma leitura que necessita ser suprida pela imaginação de quem a lê, imaginação, esta, que projete, visual e mnemonicamente, as descrições e análises do narrador. Por sua vez, em O lugre, todo o apelo sensorial que guia o espectador deve-se a um espaço concreto, pormenorizado com cenário, indumentária, cores e sons pontuais que, em conjunto, tanto reconstitui a atmosfera e a "cor local", quanto determinam um recorte particularizado do que Santareno quer tratar.

Assim, ao retomar o mote das crônicas na peça teatral, a abstração que o leitor precisa deduzir das primeiras se transforma em forma humana que se projeta na ação dramática da segunda (Assumpção, 2010). As funções dramáticas que então se instauram (Souriau, 1970), buscam 
distinguir, ao espectador, um microcosmo (tudo o que aparece em cena) de um macrocosmo (o universo referenciado pela peça) que, em tempos de ditadura, não poderia ser dialogado, mas urgia ser demonstrado. Logo, os porquês de uma peça de teatro mostram-se vinculados à necessidade premente de Santareno de descortinar sua visão de mundo à plateia.

\section{O MAR: TEXTO PRODUTOR DE SENTIDO}

Em ensaio abordando diversos aspectos do Mar na Literatura Portuguesa, Cândido Martins (1998) o define como um dos maiores elementos da Criação, que não nos deixa indiferentes à sua grandeza, mistérios, simbolismos, lendas, mitos e ilhas encantadas e utópicas. Neste contexto, sua paisagem quotidiana, férteis de associações com elementos de psicologia, tradições, literatura, arte e subsistência lusa, entre outros, dialoga tanto com as navegações quanto com as guerras e o retorno saudoso à pátria amada. Ao dar novos mundos ao mundo, portanto, o mar gera a criação do espírito universalista.

Em Bernardo Santareno, o Mar, trabalhado em diferentes oralidades nas crônicas de Nos mares do fim do mundo, bem como, na voz coletiva, intermediária entre ator e plateia, de O lugre, esclarecendo a ação dramática que estava ocorrendo, é apresentado como o representante de um conjunto de processos mentais que expressam tanto saberes acumulados quanto diversos tipos de atividades e episódios da vida social em que personagens e atores se encontram envolvidos. O mar é linguagem. Linguagem transformada em fala. Fala capturada em texto.

Em Koch (2005), tal definição de texto, similar à definição atribuída ao termo na década de 80 , traz para a situação comunicativa determinadas expectativas que ativam conhecimentos e experiências que, não restritos a traduzir entendimento em signos verbais, atuam, previamente, como construtores de sentido. Nesta perspectiva, as crônicas de Nos mares do fim do mundo podem ser concebidas como conjuntos de conhecimentos socioculturalmente determinados, e vivencialmente adquiridos, que expressam a exteriorização da vida psíquica dos personagens. Por sua vez, o texto dramático de $O$ lugre dá voz a um sistema de forças sociais e econômicas que necessitam ser raciocinadas por seus expectadores.

Em síntese, tratam-se de conhecimentos e forças sociais que, enquanto textos, precisam produzir sentidos. Nesta produção de sentido, Nos mares do fim do mundo mais sugere que reclama de condições sociais. Já O lugre, 
diferentemente, insere as reclamações e descontentamentos nas informações, explicações e interpretações de atores, subordinando o escrito ao visto.

\section{CONCLUSÃO}

As reflexões de Santareno nas crônicas de Nos mares do fim do mundo e no drama $O$ lugre, portanto, consideram, respectivamente, a oportunidade de leitor e plateia identificarem as condições reais de manutenção do ideário mítico da pesca do bacalhau pelo governo, de modo que, esclarecidas, associem tais experiências de outrem às suas próprias, na luta diária junto à família e aos amigos, auxiliando-se e a estes a sobreviver de modo minimamente digno.

$\mathrm{Na}$ ausência disso, mantidos encobertos os reais objetivos salazaristas, uma reação, um questionamento, uma problematização e um posicionamento popular jamais seriam possíveis. Em comum, em ambas se promove o exercício do confinamento e do distanciamento social, com todas as exigências e consequências que estes impõem à condição humana.

\section{REFERÊNCIAS}

ASSUMPÇÃO, M. E. O. O. Teatro X Narrativa: gêneros intercambiáveis?. Linha D'Água, [S. 1.], n. spe, p. 59-70, 2010. DOI: 10.11606/issn.22364242.v0ispep59-70. Disponível em: http://www.revistas.usp. br/linhadagua/article/view/62341. Acesso em: 30 nov. 2020.

CÂNDIDO MARTINS, J. O Mar, as Descobertas e a Literatura Portuguesa. Disponível em Letras \& Letras < http://alfarrabio.di.uminho.pt/vercial/ letras/candid02.htm> Acesso em 26 nov 2020.

CRUZ, Valdemar. Cobaias de Salazar. In: <https:/expresso.pt/sociedade/ 201706-18-Cobaias-de-Salazar> Acesso em 25 out 2020.

GARRIDO, Álvaro. O Estado Novo e as pescas: a recriação historicista de uma "tradição marítima nacional". In: TORGAL, Luís Reis; PAULO, Heloísa. Estados autoritários e totalitários e suas representações. Coimbra: IUC, 2008. Disponível em <https://digitalis-dsp.uc.pt/jspui/bitstream/10316.2/32197/1/7\%20estados\%20autorit\%C3\%A1rios.pdf?ln=pt-pt $>$ Acesso em 28 out 2020. 
$\mathrm{KOCH}$, Ingedore G. Villaça. A construção dos sentidos no discurso: uma abordagem sociocognitiva. Investigações. v.18, n. 2, 2005. Disponível em file:///C:/Users/Seven/Downloads/1478-3879-1-PB.pdf Acesso em 26 nov 2020.

LIMA, Luiz Tenório Oliveira. Freud. São Paulo: Publifolha, 2013.

LOURENÇO, Eduardo. Portugal como Destino seguido de Mitologia da Saudade. Lisboa: Gradiva, 2012.

MAGALHÃES, Maria José. Movimento feminista e educação: Portugal, décadas de 70 e 80. Oeiras: Celta Editora, 1998.

MARQUES, A. H. de Oliveira. História de Portugal: Das Revoluções Liberais aos Nossos Dias. Vol. III. Lisboa: Editorial Presença, 1998.

MENDONÇA, Fernando. Para o estudo do teatro em Portugal. São Paulo: Empresa Gráfica das Revistas dos Tribunais, 1971.

MOISÉS, Massaud. A literatura portuguesa através dos textos. São Paulo: Cultrix, 2012.

REIMAR. O lugre "Granja", do Porto. Disponível em

$<$ https://naviosenavegadores.blogspot.com/2017/04/o-lugre-granja-do-

porto.html> Acesso em 28 out 2020.

REIS, Carlos. História Crítica da Literatura Portuguesa: Do Realismo ao Post Modernismo. Volume IX. Lisboa: Verbo, 2005.

SANTARENO, Bernardo. Nos mares do fim do mundo: doze meses com os pescadores bacalhoeiros portugueses, por bancos da Terra Nova e da Groenlandia. Lisboa: Expo 98, 1997.

SANTARENO, Bernardo. O Lugre: peça em 6 quadros. Silveira, Lisboa: EPrimatur. 2019.

SANTOS, Graça. O Espetáculo Desvirtuado - O teatro português no reino de Salazar: 1933-1968. Alfragide: Editorial Caminho, 2002.

SARAIVA, António José; LOPES, Óscar. História da Literatura Portuguesa. Porto: Porto Editora, 1996.

SARAIVA, José Hermano. História concisa de Portugal. Mem Martins: Publicações Europa-América, 2011.

SELTZER, David. (National Geographic Society). Os solitários homens dos dóris. Os homens do mar de Portugal. Tradução de D. H. dos S. Alves e A. P. Marques. Centro de Estudos do Mar. Praia de Mira-Figueira da Foz. (Trabalho original em inglês publicado em 1968), 2008. 
SOURIAU, E. Les deux cent milles situations dramatiques. Paris: Flammarion, 1970.

SOUZA, Marisa Giannecchini Gonçalves de. O coro e suas ficções: Máscaras na orquestra. Araraquara: UNESP, 1997. (Tese de Doutoramento).

VYSE, Stuart A. Believing in Magic: The Psychology of Superstition. New York: Oxford University Press, 2014.

WILLETT, Jonh. O teatro de Brecht: visto de oito aspectos. Tradução Álvaro Cabral. Rio de Janeiro: Zahar Editores, 1967.

YATES, Frances A. A arte da memória. São Paulo: Editora da Unicamp, 2007.

Recebido em 9 de novembro de 2020

Aprovado em 25 de novembro de 2020

Licença: (ㄷ) (i) (ㅇ)

Rosemary Conceição dos Santos

Pós-Doutorado em Estudos Comparados de Literaturas de Língua Portuguesa pela Universidade de São Paulo. Pós-Doutorado em Literaturas de Língua Portuguesa pela Pontifícia Universidade Católica. Pós-Doutorado em Letras Clássicas e Vernáculas pela Universidade de São Paulo. PósDoutorado em Cognição, Leitura e Literatura pela Universidade de São Paulo (2009). Doutorado em Literatura Portuguesa pela Universidade de São Paulo. Mestrado em Estudos Literários pela Universidade Estadual Paulista "Júlio de Mesquita Filho".

Contato: cienciausp@usp.br

(D): https://orcid.org/ 0000-0001-7304-0511

José Aparecido da Silva

Mestre e Doutor em Psicologia pelo Instituto de Psicologia da Universidade de São Paulo e Pósdoutorado em Percepção e Psicofísica pela Universidade da Califórnia, Santa Bárbara, USA, é Professor Titular Aposentado do Departamento de Psicologia da FFCLRP-USP. Na Universidade de Coimbra é Co-Coordenador do Mestrado em Psicologia Experimental e, na Universidade Nacional de Tucumán (Argentina), é co-coordenador do Centro Associado de Pós-graduação apoiado pela CAPES (Brasil) e pela SPU (Argentina). Em 2017 criou e é o coordenador do Curso de MBA da USP Comportamento nas Organizações. Ministra no PECE USP/POLI as disciplinas Inteligência Emocional e O Processo de Liderança.

Contato: jadsilva@ffclrp.usp.br

(D): https://orcid.org/ 0000-0002-1852-369X 